\title{
Determinants and Congruence of Species Richness Patterns across Multiple Taxonomic Groups on a Regional Scale
}

\author{
Jörn Buse ${ }^{1,2}$ and Eva Maria Griebeler ${ }^{1}$ \\ ${ }^{1}$ Department of Ecology, Institute of Zoology, Johannes Gutenberg-University Mainz, Becherweg 13, 55099 Mainz, Germany \\ ${ }^{2}$ Ecosystem Analysis, Institute for Environmental Sciences, University of Koblenz-Landau, Fortstrasse 7, 76829 Landau, Germany
}

Correspondence should be addressed to Jörn Buse, joernbuse@gmx.de

Received 31 May 2011; Revised 29 August 2011; Accepted 10 October 2011

Academic Editor: Beth Okamura

Copyright ( 92012 J. Buse and E. M. Griebeler. This is an open access article distributed under the Creative Commons Attribution License, which permits unrestricted use, distribution, and reproduction in any medium, provided the original work is properly cited.

\begin{abstract}
Applying multiple generalized regression models, we studied spatial patterns in species richness for different taxonomic groups (amphibians, reptiles, grasshoppers, plants, mosses) within the German federal state Rhineland-Palatinate (RP). We aimed (1) to detect their centres of richness, (2) to rate the influence of climatic and land-use parameters on spatial patterns, and (3) to test whether patterns are congruent between taxonomic groups in RP. Centres of species richness differed between taxonomic groups and overall richness was the highest in the valleys of large rivers and in different areas of southern RP. Climatic parameters strongly correlated with richness in all taxa whereas land use was less significant. Spatial richness patterns of all groups were to a certain extent congruent but differed between group pairs. The number of grasshoppers strongly correlated with the number of plants and with overall species richness. An external validation corroborated the generality of our species richness models.
\end{abstract}

\section{Introduction}

Europe has undergone a period of environmental change and loss of biodiversity over the last decades $[1,2]$. A high level of biodiversity may help to preserve a range of options to adapt under changing environmental conditions such as climate and land-use change. Hence, studies of spatial patterns of species richness and its environmental determinants are required. Broad-scale patterns (i.e., global or continental extent and large grain size) in species richness are relatively well studied, and the determining mechanisms of patterns cover a wide range from energy and water availability [3$5]$ to historic climate and climate stability as predictors of present patterns $[6,7]$. Distribution models are frequently applied to understand the relationship between spatial patterns in species occurrence and environmental variables, (e.g., [8-11]). While broad-scale species richness patterns are mainly determined by energy and water availability, (e.g., [3-5, 12-14]), regional patterns (except of few taxonomic groups, e.g., $[15,16])$ were less frequently studied and underlying mechanisms are widely unknown. The strength of the impact of environmental variables on species distributions may differ with spatial extent and grain size [17-20] and a simple downscaling of the results found at broad spatial scales is not wise. The poor knowledge is particularly true for less studied taxonomic groups, for example, mosses, which encompass hundreds of species, but data availability on this group has only recently been improved at a national level (e.g., [21] for mosses in Germany).

Studies at the meso- or microscale (i.e., intermediate or small spatial extent and grain size) are needed to analyse the impact of water and energy availability on species richness patterns and to evaluate potential effects of climate change. Hortal et al. [19] showed for mammal assemblages that climatic gradients are stronger predictors of geographic ecological richness, that is, at broad spatial extent (areas between 1,000 and $10,000 \mathrm{~km}^{2}$ ), whereas other features such as habitat type become more important for the ecological richness of mammals at smaller spatial extent (areas between 100 and $1,000 \mathrm{~km}^{2}$, cf. also [22]). However, for other taxonomic groups, it remains unclear how much variation of regional species richness patterns is determined by climate and/or land use. Sensitivity of taxonomic groups to climate variables at a regional scale might help to assess 


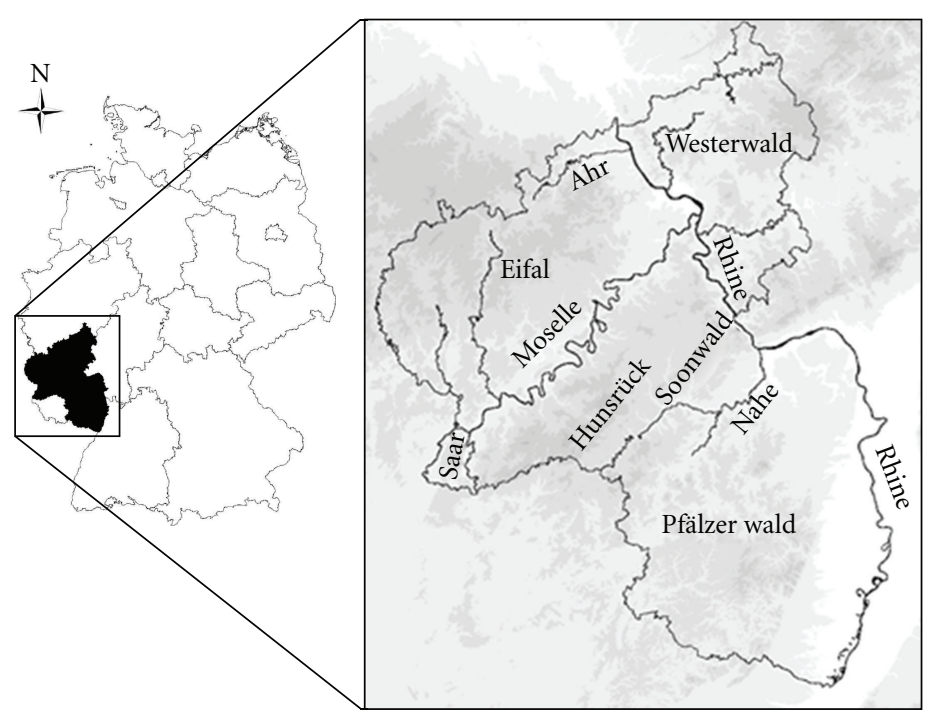

FIGURE 1: Overview map of the study region Rhineland-Palatinate (Germany) showing important rivers and mountain ranges. Palatinate is the southeastern part of Rhineland-Palatinate located southeast of the River Nahe.

effects of climatic changes on species distributions. Furthermore, conservation strategies are usually developed and implemented at smaller regional scales. Knowing whether particular taxonomic groups show congruence in spatial patterns, as this was reviewed by Heino [23] for aquatic ecosystems, is an important information for conservation.

Here, we investigate regional patterns in species richness and their environmental determinants for the poorly studied grasshoppers and mosses, and for amphibians, reptiles, and herbaceous plants in the federal state Rhineland-Palatinate in Germany. These five taxonomic groups are the only groups for which suitable data on the spatial distribution and on environmental parameters is available for the whole study region and for an adjacent region that we used to validate our results. The main questions answered in this study were as follows.

(1) Where are the centres of species richness located within the Rhineland-Palatinate?

(2) Which climatic and land-use parameters determine spatial pattern of species richness in this federal state?

(3) How congruent are regional patterns in species richness between different taxonomic groups?

We expected to find contrasting distribution patterns and different parameters being important for individual taxonomic groups. Land-use variables were expected to influence species richness distributions of all selected groups more strongly than climatic variables.

We used multiple regression models (generalized linear model, GLM) to analyse the relationship between species richness patterns and environmental variables and to identify the ecological determinants of the observed patterns. In order to determine whether the different taxonomic groups show congruence in spatial patterns of species richness at the regional scale, we analysed species richness data on the regional distribution of all five taxonomic groups.

\section{Material and Methods}

2.1. Research Area. We studied species richness patterns in the German federal state Rhineland-Palatinate (RP, Figure 1). RP is located in the southwest of Germany and covers a total area of $19,853 \mathrm{~km}^{2}$. RP is the federal state with the largest woodland cover (ca. $42 \%$ of its total area) in Germany. Due to intensive land use in some parts of RP, the woodland cover is not homogenously distributed within the federal state; particularly in the traditional vineyard regions, the proportion of woodlands is very small. RP is characterised by several low mountain ranges up to $800 \mathrm{~m}$ a.s.l. Important xerothermic sites are located in the larger valleys, for example, of the rivers Rhine, Moselle, Ahr, and Nahe, where relict and "island" populations of several endangered thermophilic reptile and insect species are found.

2.2. Modelling Species Richness. Multiple generalised linear regression models (GLMs) were established to describe the spatial distribution of species richness for each taxonomic group and to describe overall species richness (all taxonomic groups pooled). All models are based on species occurrence (presence-only) data and different environmental variables. Data on species occurrence and environmental variables were available on a grid base at the resolution of ordinance survey maps (OSM, 1:25,000). Species richness values were calculated for each grid cell based on presence-only data of species. Land cover, landscape heterogeneity, and climate variables were used as predictors in the GLMs. All models also accounted for spatial autocorrelation in the residuals [24].

Each grid cell comprised an area of approximately $130 \mathrm{~km}^{2}$. The total number of grid cells covering RP was 194. As grid cells that are located at the borders with France or Belgium are less intensively studied than others in the 
centre of the federal state and environmental and species data from the French and Belgian parts of border areas were not available to us, we included only those grid cells where more than $50 \%$ of the covered area is located in RP. In total, we omitted ten grid cells, resulting in 184 grid cells being used in our analyses.

2.3. Species Occurrence Data. Data on the distribution of different taxonomic groups in RP were derived from literature, databases, and from the State Agency for Environment of Rhineland-Palatinate. We collected literature data on reptiles $[46,47$, unpublished database of the State Agency for Environment in RP, (1960-2008)], amphibians [46, 47, unpublished database of the State Agency for Environment in RP, (1960-2008)], grasshoppers (Orthoptera) [25, (1980-2000)], vascular plants including ferns [26], and mosses [21, (1980-2007)]. For each of the grid cells, we counted the number of species per taxonomic group. Species records were simple presence data, and absence of a species in grid cells shows only that no records were available. However, our presence-only data come close to true presence-absence data, because of the comprehensive and intensive monitoring of the studied groups by experts and volunteers in RP. Although monitoring intensity of mosses is still relatively low, we decided to roughly test the first dataset on this group that is for the first time available for Germany [21]. To test our models on an independent dataset, we additionally collected analogous data on the distribution of the five taxonomic groups in the adjacent federal state Baden-Württemberg (BW, $n=291$ grid cells). For this model validation, we used the following literature sources: Günther [47] for amphibians and reptiles, Maas et al. [25] for grasshoppers, Haeupler and Schönfelder [26] for vascular plants and ferns, and Meinunger and Schröder [21] for mosses. These five taxonomic groups were selected, because species distribution data were available for both our study region $\mathrm{RP}$ and the validation region BW. We initially aimed to study further taxonomic groups such as dragonflies and butterflies, but data on the distribution of these insects was only available for BW and only existed for small geographic areas of RP.

2.4. Environmental Data. We selected 13 land-cover variables from the CORINE Land Cover 2000 dataset which is based on satellite images (see Table 1). CORINE provides additional land-cover classes for Germany, but these do not occur in our study area (e.g., peat bogs, salt meadows, etc.).

Landscape heterogeneity based on land-cover data was calculated using Simpson's diversity index $D$ :

$$
1-D=1-\sum\left(p_{i}\right)^{2}
$$

where $p_{i}$ is the proportion of the $i$ th land-cover type in a grid cell.

We used Simpson's index as a measure for landscape heterogeneity because it calculates the smaller proportions of land-cover types (e.g., small waters) in our dataset more reliably than the Shannon diversity index commonly used in other studies.
An additional topographic measure of spatial landscape heterogeneity was calculated using digital elevation data (SRTM-3). We extracted from this dataset the maximum (HTMAX, Table 1) and minimum elevation (HTMIN) for each grid cell and calculated the difference between minimum and maximum as a measure of variability in elevation (HTDIFF). The topographic variables HTMAX and HTMIN were also included in the analyses.

We also used four climate variables (Table 1) from a dataset that was explicitly established at OSM resolution for Germany [27]. This dataset is based on climate data from 2342 weather stations (German Weather Service, DWD) distributed throughout Germany. In the underlying climate model, basic climate data are homogenised and corrected for the mean elevation of the grid cells (see [27] for further explanations). We used data from the period 1961 to 1990 as for the species records-from this climate dataset to estimate mean monthly and annual values for the climatic situation in each grid cell.

Additionally, plant species richness was used as a predictor in the grasshopper model because several grasshopper species, for example, Calliptamus italicus (L., 1758) and Tetrix bipunctata (L., 1758), feed exclusively on plants that occur in habitats with high plant diversity, such as dry grasslands. Different types of grassland were not distinguished in the CORINE dataset.

2.5. Development of Species Richness Models. To calculate species richness of the taxonomic groups and overall species richness, we standardised species richness for each group, because species numbers differed strongly between groups (Table 1). We set the maximum observed species number derived from all grid cells to 100 percent for each species group and divided species numbers in each of the grid cells by this maximum. For the overall species richness, percentages in grid cells obtained for taxonomic groups were averaged. Congruence was studied between each of the taxonomic groups as well as between the taxonomic groups and combined species richness (i.e., overall species richness without the group tested). In all cases, percentages were subsequently arc-sin transformed before they were used in the multiple regression analyses [28].

Hierarchical partitioning was carried out to derive the independent contribution of the predictor variables (environmental variables) to the response variable (species richness). This statistical technique is even applicable when data are highly correlated and was used here to eliminate unimportant predictor variables [29]). In this preselection procedure, we first analysed the land cover parameters (here without water related parameters, MAR, FLW, STW; Table 1). The water-related and climate variables were analysed together in a second step, because of a limited number of variables that may be tested in the partitioning procedure. We then fitted a multiple regression model (GLM with poisson error distribution, or quasipoisson in the case of overdispersion) using all the variables that had individually contributed more than $10 \%$ to the variance in the response variable in the hierarchical partitioning 
TABLE 1: Variables used for the multiple regression modelling and multiple regression models established for species richness of different taxa. Listed are the beta coefficients and significance levels for the parameters in the final models established for five taxonomic groups. The explained variance in species richness for each taxonomic group is also shown. For spatial validation of models, the Spearman rank correlation coefficients $r$ of predicted and observed species richness values and the respective significance level are shown. ${ }^{*} P<0.05$, ${ }^{* *} P<0.01,{ }^{* * *} P<0.001$, n.s.: nonsignificant parameters in the final model that improve the explanatory power of the model (AIC).

\begin{tabular}{|c|c|c|c|c|c|c|}
\hline Variables (units) & Abbreviation & Amphibians & Reptiles & Grasshoppers & Plants & Mosses \\
\hline $\begin{array}{l}\text { Maximum observed number of } \\
\text { species/grid cell }\end{array}$ & - & 16 & 8 & 48 & 1180 & 400 \\
\hline \multicolumn{7}{|l|}{ CORINE 2000 land-cover classes } \\
\hline Deciduous forests (\%) & DEW & - & - & - & - & - \\
\hline Coniferous forests (\%) & COW & - & - & - & $-1.406^{*}$ & - \\
\hline Mixed forests (\%) & MIX & - & - & - & - & - \\
\hline Nonirrigated arable land (\%) & NIA & - & - & - & $-0.909^{*}$ & $-0.237^{* *}$ \\
\hline Vineyards (\%) & VIY & - & - & - & - & - \\
\hline Orchards (\%) & ORC & - & - & - & - & - \\
\hline Meadows and pastures (\%) & MEP & - & - & - & - & - \\
\hline Natural grasslands (\%) & NAG & - & - & - & - & - \\
\hline Heathlands (\%) & HEA & - & - & - & - & - \\
\hline Shrublands (\%) & SHR & - & - & - & - & - \\
\hline Marshes (\%) & MAR & - & - & $4.061^{*}$ & - & - \\
\hline Flowing water bodies (\%) & FLW & - & - & - & $3.052^{*}$ & - \\
\hline Standing water bodies (\%) & STW & 一 & 一 & 一 & 一 & 一 \\
\hline \multicolumn{7}{|l|}{ Topography } \\
\hline Minimum elevation within grid cell (m) & HTMIN & - & - & - & - & $-0.001^{* *}$ \\
\hline Maximum elevation within grid cell $(\mathrm{m})$ & HTMAX & - & - & $0.075^{* *}$ & - & - \\
\hline \multicolumn{7}{|l|}{ Landscape heterogeneity } \\
\hline Habitat heterogeneity ${ }^{\mathrm{b}}$ & SIMPSON & $0.374^{\text {n.s. }}$ & - & - & - & - \\
\hline Range of elevation within grid cell (m) & HTDIFF & - & - & - & - & - \\
\hline \multicolumn{7}{|l|}{ Climatic parameters 1961-1990[27] } \\
\hline Mean annual temperature $\left({ }^{\circ} \mathrm{C}\right)$ & TMPYEAR & $0.065^{*}$ & - & - & - & - \\
\hline $\begin{array}{l}\text { Mean sum of annual precipitation } \\
(\mathrm{mm})\end{array}$ & PRECYEARSUM & - & - & - & - & - \\
\hline Index of aridity ${ }^{\mathrm{a}}$ & IOA & - & - & - & - & - \\
\hline $\begin{array}{l}\text { Mean temperature of the coldest month } \\
\text { (January) }\left({ }^{\circ} \mathrm{C}\right)\end{array}$ & TMPJAN & - & - & $1.269^{* *}$ & - & $-0.064^{\text {n.s. }}$ \\
\hline Spatial autocorrelation & SAC & $0.053^{* *}$ & $0.159^{* * *}$ & $0.409^{* * *}$ & $0.078^{* * *}$ & $0.005^{* * *}$ \\
\hline Number of plant species & & not tested & not tested & $0.071^{* * *}$ & 一 & not tested \\
\hline \multicolumn{7}{|l|}{ Model accuracy and validation } \\
\hline Goodness of fit (deviance change) & & $38.36 \%$ & $33.76 \%$ & $72.73 \%$ & $62.34 \%$ & $72.6 \%$ \\
\hline $\begin{array}{l}\text { Deviance change explained by } \\
\text { environment }\end{array}$ & & $44.34 \%$ & - & $45.42 \%$ & $17.45 \%$ & $7.05 \%$ \\
\hline Deviance change explained by SAC & & $55.66 \%$ & $100 \%$ & $54.48 \%$ & $82.55 \%$ & $92.95 \%$ \\
\hline ANOVA (versus Null model) & & $F=11.826^{* * *}$ & $F=14.145^{* * *}$ & $F=69.621^{* * *}$ & $F=79.886^{* * *}$ & $F=124.61^{* * *}$ \\
\hline Spatial validation of the SAC model & & $0.758^{* * *}$ & $0.646^{* * *}$ & $0.752 * * *$ & $0.648^{* * *}$ & $0.721^{* * *}$ \\
\hline $\begin{array}{l}\text { Spatial validation of the model without } \\
\text { the SAC term) }\end{array}$ & & $0.606^{* * *}$ & - & $0.494^{* * *}$ & $0.326^{* * *}$ & $0.600^{* * *}$ \\
\hline
\end{tabular}

"mean temperature in July/mean annual sum of precipitation.

bsimpson's index of diversity using the relative proportion of the land-cover classes in grid cells.

procedure. The significance of quadratic functions of the parameters in the GLMs was also tested. We used Pearson correlations to account for collinearity among preselected predictor variables. If there were highly correlated predictor variables $(r>0.7)$ in the model, one of the variables was removed. Finally, we run an automatic stepwise procedure to delete backwards nonsignificant predictor variables from the model. Deletion of variables from the model was based on 
the AIC value of the respective model until a minimal AIC value was reached.

2.6. Residual Spatial Autocorrelation of the Models. If model residuals show spatial autocorrelation, this may bias parameter estimates and can increase type I error rates [24]. Therefore, for each species group, we first used the Rpackage "ncf" to carry out spatial autocorrelation analyses of residuals of each of the five species richness models. Spline correlograms were plotted to visualise the estimated spatial dependence of the data as a continuous function of distance [30]. We calculated 95\% confidence intervals of the estimated function using a bootstrap algorithm with 1000 resamples. Next, we added a spatial autocovariate (SAC) to our species richness models to test for significant effects of spatial autocorrelation on estimated beta values and their significance $[24,31,32]$. The autocovariate was calculated as the average species richness value of the direct neighbours for each grid cell using the R-package "spdep." Hierarchical partitioning was used to quantify the contribution of the spatial autocovariate and the environmental variables to the model.

The beta value of the added spatial autocovariate (SAC) was significant for all taxonomic groups. We thus included $\mathrm{SAC}$ as a further predictor variable in our species richness models. As the SAC variable itself is not informative with respect to the ecological determinants of species richness, we additionally tested for significant correlations between environmental variables and the SAC variable.

2.7. Model Accuracy and Validation. Model accuracy was evaluated with an ANOVA ( $F$-test) which tests for significant differences from the null model based on the change in the deviance. The deviance change itself (measured in \%) was used as a direct measure of the overall fit of the regression model.

Our final models for species richness were validated on an independent analogous dataset that we established for BW, a federal state adjacent to RP. Independent analogous datasets are considered as the best means of validating any predictive species distribution model [33-35]. Regression models were rated by correlating predicted and observed values of species richness in BW with the nonparametric Spearman's rank correlation test.

The development of all species richness models was carried out with the free software $\mathrm{R}$ version 2.9.2. All GIS work was conducted in ArcGIS 9.3 [36].

\section{Results}

3.1. Patterns of Species Richness within Taxonomic Groups. The number of amphibian species ranged from 5 to 16 (mean $=10.4)$ per grid cell, the number of reptiles from 2 to 8 per grid cell (mean $=5.4$ species), and the number of grasshoppers from 8 to 48 per grid cell $($ mean $=26.5)$ in RP. Plant species numbers varied between 181 and 1180 (mean = 728.2), and the number of moss species between 63 and 400 $($ mean $=226.0)$.
There were three main centres of species richness for amphibians: Westerwald, the Lower Nahe valley, and the Upper Rhine valley (Figure 2(a)). The Middle Rhine valley represented a major centre of reptile species richness, with a minor centre in the low mountain areas of the Soonwald and along the Nahe river (Figure 2(b)). Grasshopper richness decreased from the north of RP to the south, with the exception of the sun-exposed valleys of the large rivers (Rhine, Moselle, and Nahe), where species richness was higher. The Palatinate is the most important centre of grasshopper diversity (Figure 2(c)). Plant species richness is mainly restricted to the Middle Rhine valley and to a lesser extent to the Nahe river and Lower Saar valley (Figure 2(d)). Mosses show a distribution pattern that is different from all other studied groups with two clearly distinct centres of species richness, both of which are located in the mountainous areas of RP. Large numbers of moss species exist in the northern Eifel mountains, in the southern parts of the Hunsrück, in the Saar-Nahe mountains, and to some extent in the Pfälzer Wald (Figure 2(e)).

Overall species richness increased from the north to the south but was generally highest in the valleys of large rivers (Figure 2(f)). Centres of overall species richness were found in the Middle-Rhine region, the Saar-Moselle region, the Nahe region, and in different parts of Palatinate.

Patterns in species richness differed between taxonomic groups but were to a certain extent congruent (Figure 2, Table 2). All tested groups were significantly pair-wise correlated in terms of species richness (Table 2). While amphibians and reptiles were only weakly correlated, grasshoppers correlated strongly with plant species richness (Spearman $r=0.684, P<0.001$, Spearman rank correlation, Table 2). Grasshoppers seem to be a good indicator group for combined species richness of all other studied taxonomic groups (Spearman $r=0.716, P<0.001$, Spearman rank correlation). This observation is also confirmed in BW (model validation region), where grasshopper richness also correlated strongly with overall species richness (Spearman $r=0.514, P<0.001$, Spearman rank correlation).

3.2. Species Richness Models. For all taxonomic groups, spline correlograms of residuals of standardized species richness as well as raw species richness itself showed positive spatial autocorrelation within the first two OSM grid cells and a negative autocorrelation at greater distances. No negative spatial autocorrelation of the residuals was found at large distances for the reptile model. However, a weak negative trend in residuals was observed for all other models for larger distances ( $>10$ grid cells).

The multiple regression models including the SAC variable that were derived for each of the taxonomic groups explained between 34 (reptiles) and 73\% (grasshoppers) of the observed variability in species richness (Table 1). Climate variables were significant for amphibians, grasshoppers, and mosses, but not for reptiles and plants. Landscape heterogeneity variables (SIMPSON, HTDIFF) were only significant for amphibians. Topographical variables (minimum or maximum elevation, HTMIN, HTMAX) significantly correlated with species richness of grasshoppers and of mosses. 


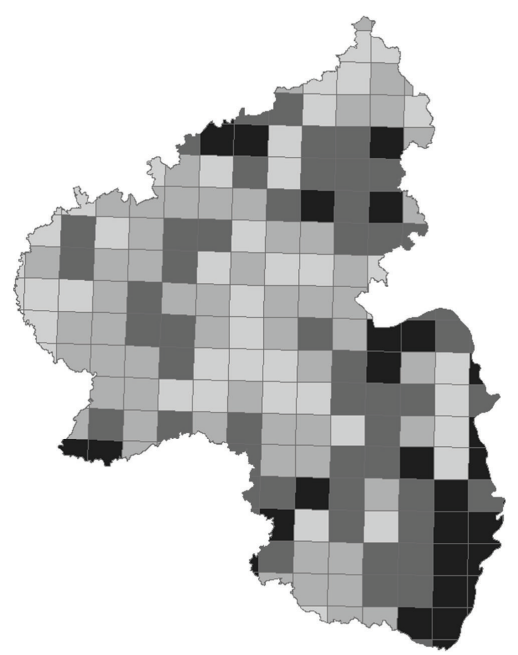

Number of amphibian species

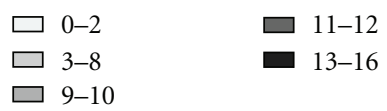

(a)

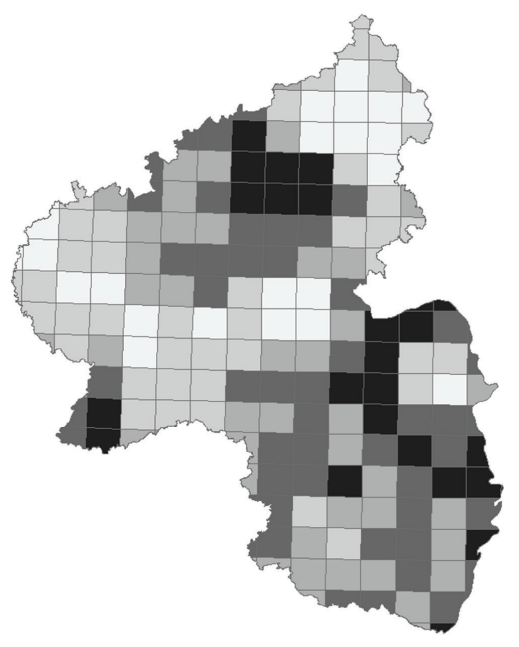

Number of plant species

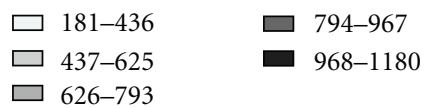

(d)

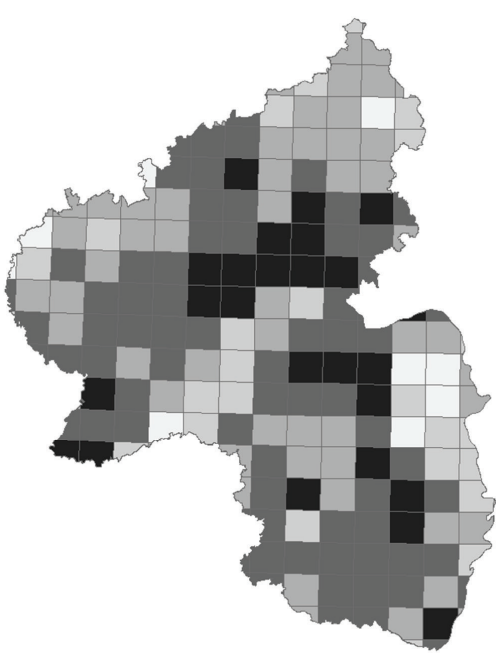

Number of reptile species

$\square 2-3$
$\square 4$
$\square 5$

$\square 6$

-7-8

(b)

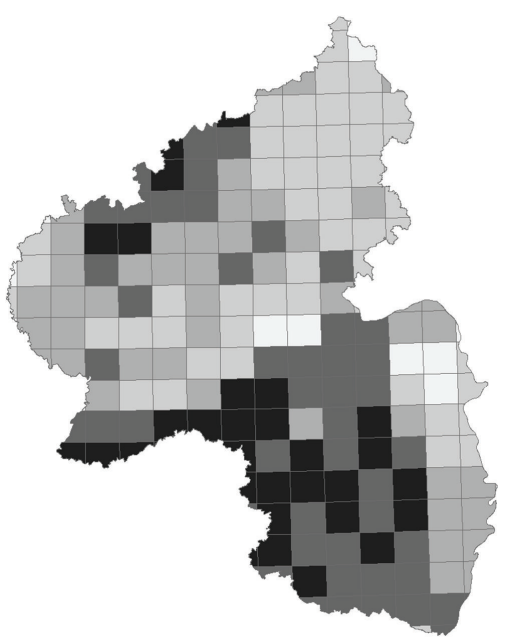

Number of moss species

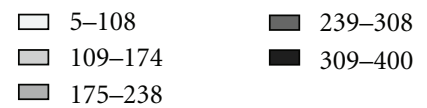

(e)

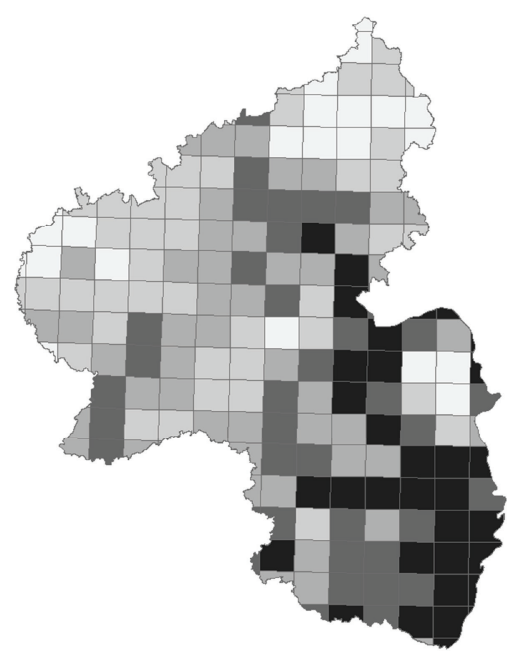

Number of grasshopper species

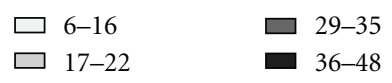

(c)

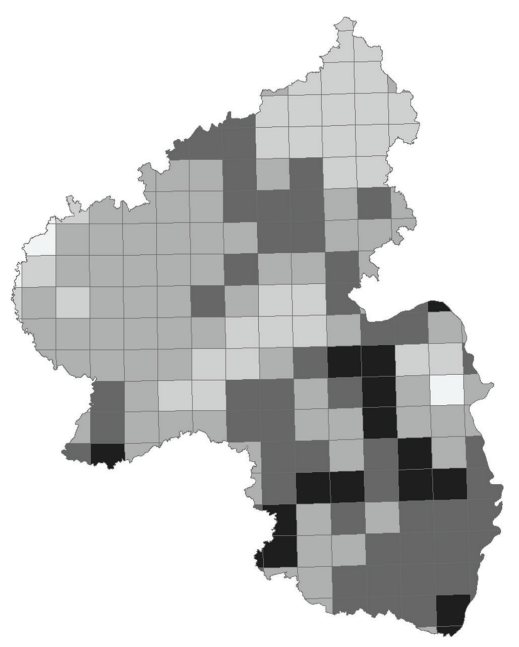

Index of overall species richness

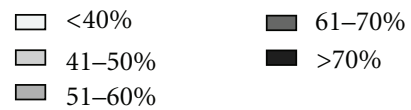

(f)

FIGURE 2: Species richness patterns of amphibians (a), reptiles (b), grasshoppers (c), plants (d), mosses (e), and overall species richness (f) among the tested taxonomic groups in Rhineland-Palatinate at the OSM resolution.

Landscape heterogeneity (SIMPSON) significantly affected only amphibian species richness (Table 1). TMPYEAR (mean annual temperature) was the most important predictor of amphibian species richness and explained $23 \%$ of the deviance change compared to the null model. As the SAC itself does not contain any useful ecological information, we carried out additional tests to rate correlations between SAC and environmental variables. Important variables found indirectly determining amphibian species richness via SAC were the cover percentage of standing water in the grid cells (STW, $r_{\text {Pearson }}=0.406, P<0.001$ ), the mean temperature in January (TMPJAN, $r_{\text {Pearson }}=0.482, P<0.001$ ), and the maximum elevation within the grid cells $\left(\right.$ HTMAX, $r_{\text {Pearson }}=$ $-0.511, P<0.001)$.

None of the environmental variables analysed did directly influence reptile species richness, but the effect of the 
TABLE 2: Spearman rank correlations for the species richness of the different taxonomic groups in Rhineland-Palatinate (modelled region) and Baden-Württemberg (the adjacent region used for model validation). We used arcsin-transformed data to calculate correlations. ${ }^{* * *} P<$ $0.001,{ }^{*} P<0.01,{ }^{*} P<0.05$, n.s.: not significant.

\begin{tabular}{|c|c|c|c|c|c|}
\hline & All other species ${ }^{\mathrm{a}}$ & Amphibians & Reptiles & Grasshoppers & Plants \\
\hline \multicolumn{6}{|c|}{ Rhineland-Palatinate } \\
\hline Amphibians & $0.455^{* * *}$ & - & & & \\
\hline Reptiles & $0.420^{* * *}$ & $0.187^{*}$ & - & & \\
\hline Grasshoppers & $0.716^{* * *}$ & $0.489^{* * *}$ & $0.452^{* * *}$ & - & \\
\hline Plants & $0.678^{* * *}$ & $0.450^{* * *}$ & $0.365^{* * *}$ & $0.684^{* * *}$ & - \\
\hline Mosses & $0.452^{* * *}$ & $0.219^{* *}$ & $0.348^{* * *}$ & $0.393^{* * *}$ & $0.421^{* * *}$ \\
\hline \multicolumn{6}{|c|}{ Baden-Württemberg } \\
\hline Amphibians & $0.431^{* * *}$ & - & & & \\
\hline Reptiles & $0.467^{* * *}$ & $0.333^{* * *}$ & - & & \\
\hline Grasshoppers & $0.514^{* * *}$ & $0.345^{* * *}$ & $0.387^{* * *}$ & - & \\
\hline Plants & $0.275^{* * *}$ & $0.417^{* * *}$ & 0.030 n.s. & $0.323^{* * *}$ & - \\
\hline Mosses & $0.282^{* * *}$ & 0.005 n.s. & $0.440^{* * *}$ & $0.186^{* *}$ & 0.007 n.s. \\
\hline
\end{tabular}

${ }^{a}$ Combined species richness of all other studied taxonomic groups.

SAC variable was significant. Positive correlations existed between SAC and the proportion of woodland (DEW, $r_{\text {Pearson }}=0.308, P<0.001 ;$ MIX, $r_{\text {Pearson }}=0.255, P<$ $0.001)$ and between SAC and the proportion of orchards (ORC, $\left.r_{\text {Pearson }}=0.168, P=0.022\right)$. SAC was negatively correlated with the proportion of meadows and pastures (MEP, $\left.r_{\text {Pearson }}=-0.357, P<0.001\right)$, the mean sum of annual precipitation (PRECYEARSUM, $r_{\text {Pearson }}=-0.234$, $P=0.001)$, and the proportion of marshes (MAR, $r_{\text {Pearson }}=$ $-0.226, P=0.002)$. Topographical landscape structure impacted reptile richness indirectly via SAC, which decreased slightly with increasing minimum elevation levels in the grid cells (HTMIN, $\left.r_{\text {Pearson }}=-0.194, P=0.008\right)$.

The number of grasshopper species correlated positively with the mean temperature in January (TMPJAN) and with maximum elevation (HTMAX, Table 1). SAC was, for example, significantly negatively correlated with the proportion of meadows and pastures (MEP, $r_{\text {Pearson }}=-0.664, P<0.001$ ). This negative correlation was not considered as a single predictor in the final model but should be discussed because of the strength of the relationship (Figures 3(a) and 3(b)).

Plant species richness was strongly positively correlated with grasshopper species richness (Table 2). Plant species richness itself correlated negatively with the proportion of coniferous forests (COW), but positively with increasing proportions of flowing water bodies (FLW). The SAC of plant species richness was, for example, significantly positively correlated with mean annual temperature (TMPYEAR) and aridity (see the relationship between plant species richness and aridity (IOA) in Figure 3(c)) but negatively correlated with mean annual precipitation.

The main parameters influencing moss species richness patterns in the final model were mean temperature in January (TMPJAN), the proportion of nonirrigated agricultural areas, and the minimum elevation in the grid cell. However, these three parameters explained only $7 \%$ of the variability in species richness, whereas the remaining variability (93\%) was explained by the SAC. The SAC for moss species richness was significantly correlated to a couple of different environmental and climatic variables. The most important of these were mean annual temperature (TMPYEAR) and aridity (IOA), which had a negative relationship with the SAC. The final model explained $73 \%$ of the variation in moss species richness. A quadratic relationship between the SAC and mean annual precipitation (PRECYEARSUM) was obtained from our dataset (Figure 3(d)). The highest species numbers (>350 species) were found in regions with an annual precipitation ranging between 650 and $1100 \mathrm{~mm}$. The richness of moss species was lower in regions showing more than $1100 \mathrm{~mm}$ and less than $600 \mathrm{~mm}$ annual precipitation.

A change from high levels of plant species richness at lower elevations to higher levels of moss species richness at higher elevations was found in RP, as the moss species to plant species ratio increased with increasing mean elevations (Pearson correlation, $r=0.537, P<0.001$ ).

3.3. Evaluation of the Fitted Species Richness Models on an Independent Dataset. We validated our final species richness models established for RP (both with and without the spatial autocovariate) by applying them to analogous external datasets existing for BW. Predicted and observed values of species richness in all five taxonomic groups significantly correlated with each other in BW (Spearman rank correlation coefficient), but accuracy of predictions varied between taxonomic groups (Table 1). When SAC was included in the models, the correlation was the highest for both amphibians (Spearman correlation, $r=0.758, P<$ $0.001)$ and grasshoppers $(r=0.752, P<0.001)$, followed by mosses $(r=0.721, P<0.001)$, and it was the lowest for both reptiles $(r=0.646, P<0.001)$ and plants $(r=$ 0.648, $P<0.001)$. All models established for RP showed only a moderate transferability to BW when the SAC term was removed from the models (Table 1). In this case, an 


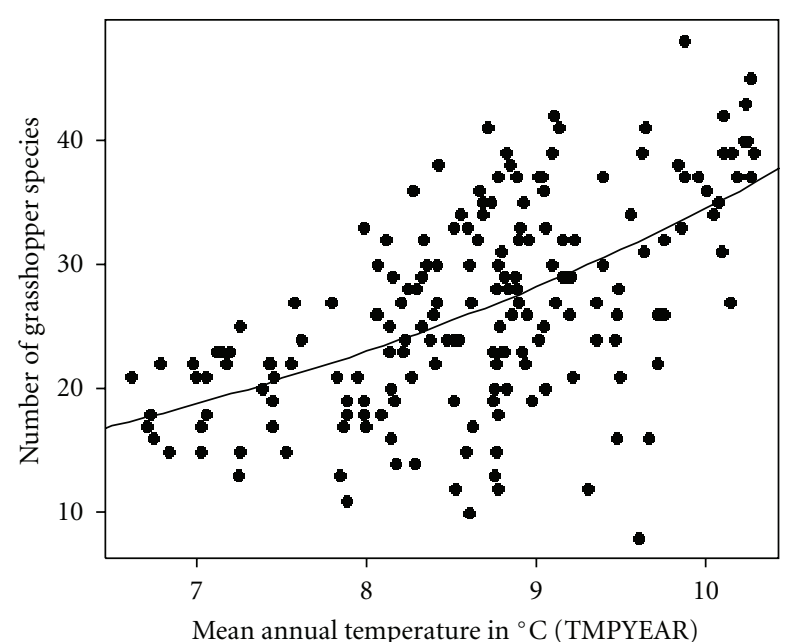

(a)

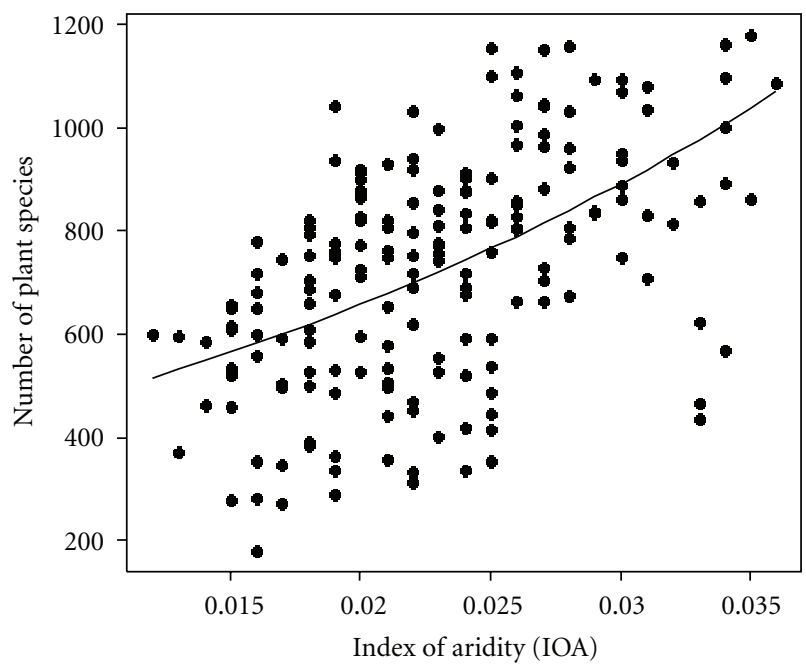

(c)

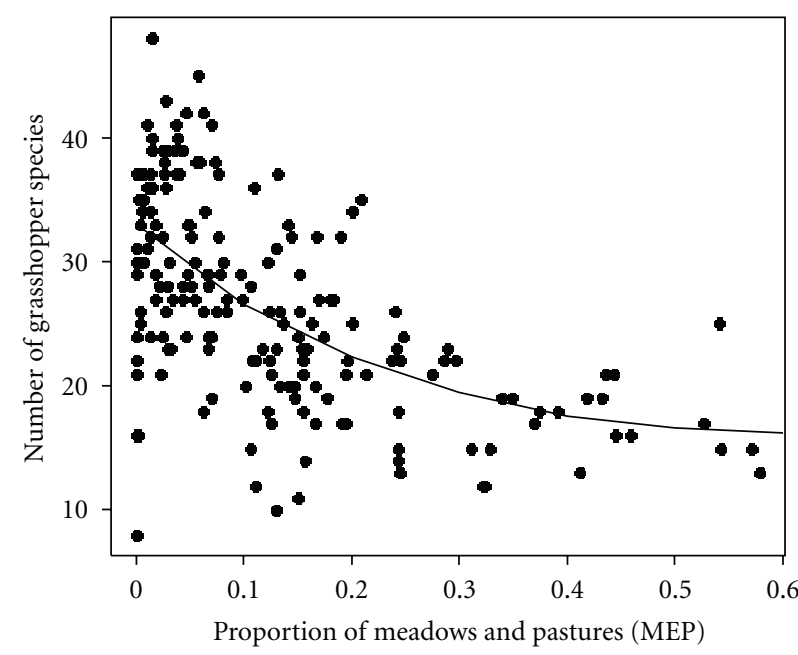

(b)

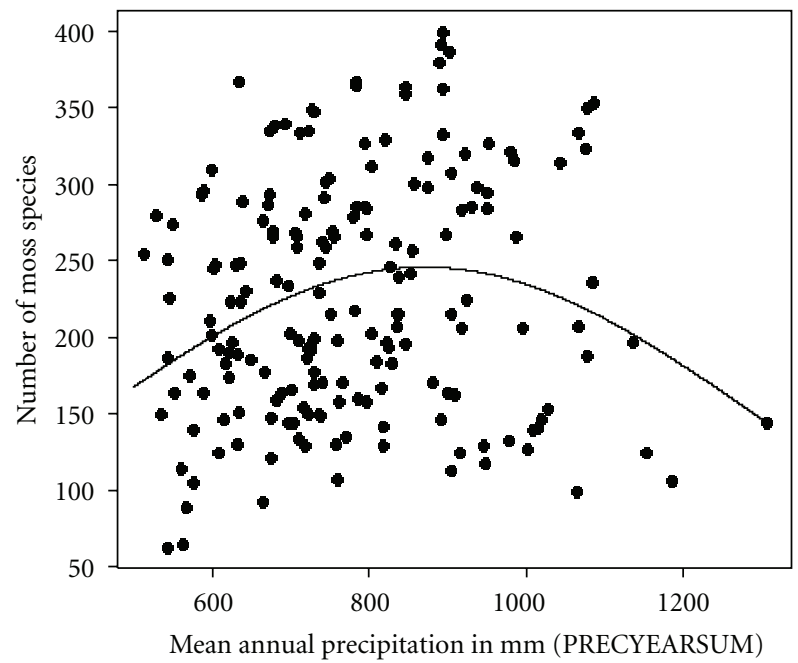

(d)

FIgURE 3: Correlations of species richness for different taxa with environmental parameters in 184 grid cells: (a) number of grasshopper species and mean annual temperature, GLM (with poisson errors), 32\% deviance change, $P<0.001$, (b) number of grasshopper species and proportion of meadows and pastures, GLM (with poisson errors), 36\% deviance change, $P<0.001$, (c) number of plant species and index of aridity, GLM (with quasipoisson errors), $23 \%$ deviance change, $P<0.001$, (d) number of moss species and mean sum of annual precipitation, GLM (with quasipoisson errors), $6 \%$ deviance change, $P<0.01$.

overestimation of low species numbers and underestimation of large species numbers was observed for all tested models.

\section{Discussion}

4.1. Model Accuracy. Our models which took land-cover, topographical, and climatic variables into account explained between 34 and $73 \%$ of the variation in species richness of the five taxonomic groups. This level of explanative power coincides with other studies on species richness at a microor mesoscale (max. 65\% explained variance, e.g., $[15,16]$ with grid cell sizes $5 \times 5 \mathrm{~km}$ ), but studies of species richness patterns on a macroscale (= large spatial extent and large grain size) showed much higher levels (e.g., $[37,38]$ which used provinces or countries). The same pattern in which models at a macroscale prove to be more accurate is apparent when correlations of species numbers between different taxonomic groups are studied. For China, Qian [37] showed that amphibian (reptile) and plant species richness is higly correlated $\left(r_{\text {Pearson }}=0.9\right.$ for amphibians; $r_{\text {Pearson }}=0.7$ for reptiles), whereas Maes et al. [15] found a lower correlation $\left(r_{\text {Spearman }}=0.3\right)$ for the same groups in a study that was conducted at a smaller grain size in the small province of Flanders, Belgium. The strength of the correlations found in our study RP between plant species richness and amphibians $\left(r_{\text {Spearman }}=0.45\right)$ or reptiles $\left(r_{\text {Spearman }}=0.36\right)$ coincides with the amount found for the Flanders region, Belgium [15]. The causal mechanisms for varying strength in species richness correlations over spatial scales are poorly understood [39]. We believe that the differences in the strength of correlations 
at different spatial scales probably result from an increasing influence of dispersal constraints and population processes on species distributions at smaller grain size. Extinction and recolonisation dynamics in metapopulations might be a good example, where not all suitable patches are colonised by a species. Forces such as intensive management and habitat simplification might also bias richness patterns found in natural environments at smaller grain size [40]. There are several further reasons explaining the lower performance of the models developed for smaller grain sizes or for smaller spatial extent [18]. First, soil parameters varying at different spatial scales were not tested in our approach but have been shown to significantly influence model accuracy [16]. Second, other important variables explaining richness patterns could be still missing, as most of the models, even in other studies, rarely explain more than $50 \%$ of the total variability. Finally, a geographic variation in sampling effort may exist [41] as well as different sampling efforts concerning the taxa itself. However, species distribution models express a tradeoff between practicability and data quality as most data used for modelling are averages of a time period. Species distributions may shift, and climatic trends may arise within such a period, but this is never reflected in the data.

We used a spatial validation on an independent dataset to evaluate our models. Different validation approaches for species distribution models have been applied in the past, for example, division of the dataset into a training and a test subset, internal bootstrapping, and so forth (for an overview, see $[33,34,42])$. It is, however, suggested by the previously named authors that the use of an independent dataset is the best approach to test the predictive ability of a model. Our spatial validation revealed that the same predictor variables can be used at least for Baden-Württemberg to sufficiently predict species richness. Predictions were relatively bad when the SAC term was not included in the model that shows that spatial autocorrelation has to be considered in analyses of species distributions [24]. Further analyses should be started in RP to find regions that are underinvestigated using the discrepancy between observed and predicted species richness [43].

4.2. Spatial Distribution of Species Richness and Its Determinants. In general, the climatic variables are a major determinant of variation in species richness at the regional extent of RP. The importance of climatic variables for the distribution of species richness differed in previous studies that used a smaller grain size (e.g., grid cell sizes $5 \times 5 \mathrm{~km}$, [15, 16]). This difference could be explained by the preselection of variables that had been considered as predictors for models. Our models suggest that environmental heterogeneity (elevational gradient, landscape heterogeneity) is very important for the spatial distribution of amphibians, and to a lesser extent important for grasshoppers. Maes et al. [15] found a positive correlation between species richness and biotope diversity for plants, dragonflies, herpetofauna, butterflies, and birds. The data presented by Schouten et al. [16] reveal the same trend for grasshoppers, dragonflies, and mosses that was observed by Maes et al. [15], but not for hoverflies and the herpetofauna. Amphibians use a broad range of habitats (from woodlands to wet meadows) but generally need access to ponds, streams, or wetlands for reproduction. Proportions of wetlands of any type are positively associated with habitat heterogeneity in RP and may contribute to higher observed amphibian species richness in more heterogeneous landscapes [44].

In our study, plant species richness was not a good indicator of reptile species richness, although plant species richness had turned out to be relatively well correlated with ants, spiders, gastropods, orthopterans, and birds at a smaller grain size in another study [45]. However, in RP, reptiles comprise a low number of species. We found several indirect correlations between environmental variables and reptile species richness. Among these were the proportion of meadows and pastures (MEPs) and the maximum elevation (HTMAX), both of which had a negative effect on reptile occurrence. Areas of RP with a high number of reptile species are typically highly structured landscapes, whereas intensive forestry and agriculture lead to speciespoor reptile assemblages [46]. Higher elevations and higher annual precipitation also had an indirect negative impact on reptile species richness, indicating that the most favourable conditions for reptiles exist at low elevations and under relatively dry conditions in RP (most reptile species are xerothermic; [47]).

Only a small proportion of the variability in moss species richness was directly explained by environmental variables, whereas the largest proportion was explained by the SAC. The SAC primarily accounts for the spatial information which cannot be explained by the other predictors used in the model [24]. When SAC takes over much of the explained variability in a model, as this was the case for mosses, one is interested in the ecological information behind. The SAC in the model for mosses showed a strong negative correlation relation with mean annual temperature and aridity, indicating that these parameters are important determinants for moss species richness. Mosses are likely to be sensitive to aridity or the availability of water, because their reproduction cycle depends on high levels of humidity. The impact of the range of elevation on species richness of mosses, expressed by a positive correlation between this range and the SAC, shows that mosses have adapted to a variety of different habitats and that they thus benefit from landscape heterogeneity. Mosses are more frost resistant than herbaceous plants [48] and should be at an advantage with respect to survival at higher elevations where frost events are more frequent. This might be reflected in the moss species to plant species ratio increasing with mean elevation of the studied grid cells. Environmental correlations with SAC are of the same magnitude as the direct correlation between species numbers and environmental variables, which shows that conditions in the neighboring grid cells are often similar. Whether conditions in the surrounding cells have an effect on species richness in the focussed grid cells is not clear. Recorder effort might bias species distribution patterns [49]. In general, we are aware that recorder effort and monitoring of mosses are still far from being spatially homogenous within Germany. Present patterns analysed 
here are certainly somehow biased by varying recorder effort in different geographic regions.

Grasshoppers consist of several stenotopic species and are found almost exclusively in open habitats. Landscape heterogeneity may be important for grasshoppers at a microscale, that is, in datasets that use finer resolutions than CORINE or in datasets that use smaller grid cells $\left(25 \mathrm{~km}^{2}\right.$ grid cells in Schouten et al. [16]). Habitat heterogeneity was the strongest predictor of grasshopper species richness in the Netherlands and explained 30\% of the total variation [16]. In this study, plant species richness was the strongest predictor of the spatial variation in grasshopper richness, when plant species richness was included as a further predictor in the model using abiotic variables before only. The model which takes into account plant species richness in addition to other environmental predictors and SAC explains more than $72 \%$ of the variation in grasshopper species richness. Plant and grasshopper species also showed a high correlation at landscape scale in Austria $\left(r_{\text {Pearson }}=0.77,[45]\right)$. It has been shown for Europe that the number of Caelifera species (a suborder of grasshoppers) is associated with variability in plant species richness at country level [50]. In RP, large numbers of plants were found in regions with increasing values of aridity. In Switzerland, floristic species richness is mainly influenced by a temperature gradient [51]; in our study, such a temperature gradient was highly correlated with aridity (IOA) in RP (TMPYEAR and IOA, $r_{\text {Pearson }}=0.730$, $P<0.001)$.

\subsection{How Important Are Climatic Parameters for Species Rich-} ness Patterns at Regional Scales? Applying only climatic variables, Bakkenes et al. [52] were able to explain $42 \%$ of the variation in European plant species richness. Climatic variables have been shown to be similar important for mammals, amphibians, and birds in Europe [12]. Araújo et al. [6] have recently shown that the diversity patterns of amphibians and reptiles in Europe are better explained by the stable climatic conditions during the last 20,000 years than by the contemporary climatic situation. These observations suggest that large-scale variation in species richness seems to be mainly driven by climatic parameters [19]. Scaling down to smaller grain size $(1 \times 1 \mathrm{~km})$, Soares and Brito [44] showed that richness patterns of amphibians and reptiles are well explained by precipitation, water surfaces per grid cells, and tree diversity cover. We found a similar trend in RP where landscape heterogeneity is a predictor of amphibian species richness, although mean annual temperature was still the strongest predictor. Species richness patterns of the five taxonomic groups studied in RP suggest that climatic variables, particularly the annual minimum temperatures, were the most important determinants of richness; this observation was in contrast to other studies with regional extent $[15,16]$. One explanation is that RP comprises a stronger geographic variation in climate (TMPYEAR ranges from 6.6 to $10.3^{\circ} \mathrm{C}$ ) and topography (mean elevation in grid cells ranges from 89 to $580 \mathrm{~m}$ a.s.l.) than the Flanders [15] and the Netherlands [16] analysed in these studies.

We conclude that land-cover variables are likely to become more important at small grain size than at large grain size. Climatic parameters represent large proportions of the variability in species richness at smaller grain sizes (cf. $[8,44]$ ) and at regional extent [5]. However, a certain amount (here $>30 \%$ ) of unexplained variability in species richness patterns remains in the species richness data, even if spatial autocorrelation in the residuals is incorporated in the models.

4.4. Congruence of Spatial Patterns. Even at a regional extent reliable distribution data for the majority of taxonomic groups are simply not available. The lack of data for less "popular" taxonomic groups leads to conservation strategies that are only based upon a selection of charismatic species that are easy to survey. The use of indicator taxa is considered as an approach to overcome this problem $[53,54]$. Correlations between different invertebrate groups at small grain size ( 1 ha plots) seem to be very weak and no surrogate group for invertebrate species diversity has been found [55]. At large grain size (country level), patterns in richness and endemism of highly diverse insects such as ground beetles were found to be highly correlated with those of plants, amphibians, and reptiles [56]. For nature conservation, the congruence of spatial patterns in species richness between less studied taxonomic groups, for example, mosses and most invertebrate groups, and popular groups, such as amphibians and reptiles, still has to be tested on small spatial extent and on small grain size.

We found congruence of spatial patterns in species richness among the five taxonomic groups for RP. The highest correlation was observed between grasshopper and plant species richness. These findings contradict species richness patterns described by Duelli and Obrist [57] at a microscale $(5 \mathrm{~km}$ transect) for several invertebrate taxa, and also patterns of plants, reptiles, and amphibians analysed on a national level in China (Qian [37] which used national provinces as units) and even at a global scale (Qian and Ricklefs [38] which used countries and regions as units). However, the congruence patterns that were found for the five taxonomical groups in RP may change at different grain size (grid cell sizes $19,000 \mathrm{~km}^{2}$ and $75,000 \mathrm{~km}^{2}$ ), as has been shown for the relationship between birds and butterflies [58].

Invertebrates are more efficient predictors of species richness patterns than vertebrates [59]. In RP, grasshopper richness correlated to species richness for all other taxonomic groups $\left(r_{\text {Pearson }}=0.716\right)$. When selecting surrogates for species richness, a critical correlation coefficient higher than 0.75 has been recommended [55]. As our correlation is even somewhat lower than this threshold, we suggest a careful use of grasshoppers as an indicator group for species richness in further studies. Neverthess, grasshoppers are easy to survey, and their monitoring is less time consuming than of other taxa. A further advantage of grasshoppers is their restricted diversity in Europe (Fauna Europaea [60]: e.g., Switzerland 109 species, Germany 83 species, Hungary 123 species, Belgium 51 species). However, grasshopper species richness must not necessarily be an indicator for other taxonomic groups than those tested here. Particularly rare and protected species might not occur in most species-rich grid cells [61]. 
A multitaxa approach could be more appropriate to assess overall species richness patterns in diverse habitats.

\section{Acknowledgments}

This study was funded within the project "Klima- und Landschaftswandel in Rheinland-Pfalz (KlimLandRP)" by the "Ministerium für Umwelt, Forsten und Verbraucherschutz" of Rhineland-Palatinate, Germany. The authors thank Oliver Dürhammer for kindly providing the moss data from his database. Many thanks to Franz Badeck for his support in the usage of climate data from the TKCLIM-database. The authors also thank Rüdiger Burkhardt and Michael Altmoos (Landesamt für Umwelt in Rheinland-Pfalz) for providing distribution data for numerous species. The authors are indebted to Thorsten Assmann and an anonymous referee for their comments on an earlier draft of the manuscript.

\section{References}

[1] T. Kull and M. J. Hutchings, "A comparative analysis of decline in the distribution ranges of orchid species in Estonia and the United Kingdom," Biological Conservation, vol. 129, no. 1, pp. 31-39, 2006.

[2] S. Prieto-Benitez and M. Mendez, "Effects of land management on the abundance and richness of spiders (Araneae): a meta-analysis," Biological Conservation, vol. 144, pp. 683-691, 2011.

[3] J. A. F. Diniz-Filho, T. F. L. V. B. Rangel, and B. A. Hawkins, "A test of multiple hypotheses for the species richness gradient of South American owls," Oecologia, vol. 140, no. 4, pp. 633-638, 2004.

[4] O. D. Finch, T. Blick, and A. Schuldt, "Macroecological patterns of spider species richness across Europe," Biodiversity and Conservation, vol. 17, no. 12, pp. 2849-2868, 2008.

[5] H. Qian, "Environment-richness relationships for mammals, birds, reptiles, and amphibians at global and regional scales," Ecological Research, vol. 25, no. 3, pp. 629-637, 2010.

[6] M. B. Araújo, D. Nogues-Bravo, J. A. F. Diniz-Filho, A. M. Haywood, P. J. Valdes, and C. Rahbek, "Quaternary climate changes explain diversity among reptiles and amphibians," Ecography, vol. 31, no. 1, pp. 8-15, 2008.

[7] J. J. Wiens and M. J. Donoghue, "Historical biogeography, ecology and species richness," Trends in Ecology and Evolution, vol. 19, no. 12, pp. 639-644, 2004.

[8] A. Guisan and U. Hofer, "Predicting reptile distributions at the mesoscale: relation to climate and topography," Journal of Biogeography, vol. 30, no. 8, pp. 1233-1243, 2003.

[9] J. M. Finch, M. J. Samways, T. R. Hill, S. E. Piper, and S. Taylor, "Application of predictive distribution modelling to invertebrates: odonata in South Africa," Biodiversity and Conservation, vol. 15, no. 13, pp. 4239-4251, 2006.

[10] L. Boitani, I. Sinibaldi, F. Corsi et al., "Distribution of medium- to large-sized African mammals based on habitat suitability models," Biodiversity and Conservation, vol. 17, no. 3, pp. 605-621, 2008.

[11] J. Müller, J. Pöllath, R. Moshammer, and B. Schröder, "Predicting the occurrence of Middle Spotted Woodpecker Dendrocopos medius on a regional scale, using forest inventory data," Forest Ecology and Management, vol. 257, no. 2, pp. 502-509, 2009.
[12] R. J. Whittaker, D. Nogués-Bravo, and M. B. Araújo, "Geographical gradients of species richness: a test of the waterenergy conjecture of Hawkins et al. (2003) using European data for five taxa," Global Ecology and Biogeography, vol. 16, no. 1, pp. 76-89, 2007.

[13] A. Baselga, "Determinants of species richness, endemism and turnover in European longhorn beetles," Ecography, vol. 31, no. 2, pp. 263-271, 2008.

[14] A. Schuldt and T. Assmann, "Environmental and historical effects on richness and endemism patterns of carabid beetles in the western Palaearctic," Ecography, vol. 32, no. 5, pp. 705$714,2009$.

[15] D. Maes, D. Bauwens, L. De Bruyn et al., "Species richness coincidence: conservation strategies based on predictive modelling," Biodiversity and Conservation, vol. 14, no. 6, pp. 13451364, 2005.

[16] M. A. Schouten, P. A. Verweij, A. Barendregt, R. M. J. C. Kleukers, V. J. Kalkman, and P. C. De Ruiter, "Determinants of species richness patterns in the Netherlands across multiple taxonomic groups," Biodiversity and Conservation, vol. 18, no. 1, pp. 203-217, 2009.

[17] M. Altmoos, "Erkennen wir die richtigen habitate von tieren? Räumliche skalen der habitatpräferenz und skalierte habitatmodelle in fallstudien mit amphibien und heuschrecken," Naturschutz und Landschaftsplanung, vol. 35, no. 7, pp. 212218, 2003.

[18] C. Rahbek, "The role of spatial scale and the perception of large-scale species-richness patterns," Ecology Letters, vol. 8, no. 2, pp. 224-239, 2005.

[19] J. Hortal, J. Rodriguez, M. Nieto-Diaz, and J. M. Lobo, "Regional and environmental effects on the species richness of mammal assemblages," Journal of Biogeography, vol. 35, no. 7, pp. 1202-1214, 2008.

[20] P. Janssen, D. Fortin, and C. Hébert, "Beetle diversity in a matrix of old-growth boreal forest: influence of habitat heterogeneity at multiple scales," Ecography, vol. 32, no. 3, pp. 423-432, 2009.

[21] L. Meinunger and W. Schröder, Verbreitungsatlas der Moose Deutschlands, Edited by O. Dürhammer, Regensburgische Botanische Gesellschaft von 1790, 2007.

[22] M. Luoto, R. Virkkala, and R. K. Heikkinen, "The role of land cover in bioclimatic models depends on spatial resolution," Global Ecology and Biogeography, vol. 16, no. 1, pp. 34-42, 2007.

[23] J. Heino, "Are indicator groups and cross-taxon congruence useful for predicting biodiversity in aquatic ecosystems?" Ecological Indicators, vol. 10, no. 2, pp. 112-117, 2010.

[24] C. F. Dormann, J. M. McPherson, M. B. Araujo et al., "Methods to account for spatial autocorrelation in the analysis of species distributional data: a review," Ecography, vol. 30, no. 5, pp. 609-628, 2007.

[25] S. Maas, P. Detzel, and A. Staudt, Gefährdungsanalyse der Heuschrecken Deutschlands Verbreitungsatlas, Gefährdungseinstufung und Schutzkonzepte, Landwirtschaftsverlag, Godesberg, Germany, 2002.

[26] H. Haeupler and P. Schönfelder, Atlas der Farn- und Blütenpflanzen der Bundesrepublik Deutschland, Ulmer, Stuttgart, Germany, 2nd edition, 1989.

[27] F. W. Badeck, S. Pompe, and I. Kühn, "Wetterextreme und artenvielfalt. Zeitlich hochauflösende Klimainformationen auf dem Messtischblattraster und für Schutzgebiete Deutschlands," Naturschutz und Landschaftsplanung, vol. 40, pp. 343$345,2008$. 
[28] C. Krebs, Ecological Methodology, Benjamin Cummings, Menlo Park, Calif, USA, 2nd edition, 1999.

[29] R. Mac Nally and C. J. Walsh, "Hierarchical partitioning public-domain software," Biodiversity and Conservation, vol. 13, no. 3, pp. 659-660, 2004.

[30] O. N. Bjørnstad and W. Falck, "Nonparametric spatial covariance functions: estimation and testing," Environmental and Ecological Statistics, vol. 8, no. 1, pp. 53-70, 2001.

[31] N. H. Augustin, M. A. Mugglestone, and S. T. Buckland, "An autologistic model for the spatial distribution of wildlife," Journal of Applied Ecology, vol. 33, no. 2, pp. 339-347, 1996.

[32] M. Luoto, M. Kuussaari, H. Rita, J. Salminen, and T. Von Bonsdorff, "Determinants of distribution and abundance in the clouded apollo butterfly: a landscape ecological approach," Ecography, vol. 24, no. 5, pp. 601-617, 2001.

[33] A. Guisan and N. E. Zimmermann, "Predictive habitat distribution models in ecology," Ecological Modelling, vol. 135, no. 2-3, pp. 147-186, 2000.

[34] S. Manel, H. Ceri Williams, and S. J. Ormerod, "Evaluating presence-absence models in ecology: the need to account for prevalence," Journal of Applied Ecology, vol. 38, no. 5, pp. 921931, 2001.

[35] I. P. Vaughan and S. J. Ormerod, "The continuing challenges of testing species distribution models," Journal of Applied Ecology, vol. 42, no. 4, pp. 720-730, 2005.

[36] Esri, ArcGIS 9.3, Environmental Systems Research Institute, Redlands, Calif, USA, 2008.

[37] H. Qian, "Relationships between plant and animal species richness at a regional scale in China," Conservation Biology, vol. 21, no. 4, pp. 937-944, 2007.

[38] H. Qian and R. E. Ricklefs, "Global concordance in diversity patterns of vascular plants and terrestrial vertebrates," Ecology Letters, vol. 11, no. 6, pp. 547-553, 2008.

[39] V. Wolters, J. Bengtsson, and A. S. Zaitsev, "Relationship among the species richness of different taxa," Ecology, vol. 87, no. 8, pp. 1886-1895, 2006.

[40] A. C. Weibull, O. Ostman, and A. Granqvist, "Species richness in agroecosystems: the effect of landscape, habitat and farm management," Biodiversity and Conservation, vol. 12, no. 7, pp. 1335-1355, 2003.

[41] R. L. H. Dennis and C. D. Thomas, "Bias in butterfly distribution maps: the influence of hot spots and recorder's home range," Journal of Insect Conservation, vol. 4, no. 2, pp. 73-77, 2000.

[42] A. H. Fielding and J. F. Bell, "A review of methods for the assessment of prediction errors in conservation presence/ absence models," Environmental Conservation, vol. 24, no. 1, pp. 38-49, 1997.

[43] J. M. Lobo and F. Martin-Piera, "Searching for a predictive model for species richness of Iberian dung beetle based on spatial and environmental variables," Conservation Biology, vol. 16, no. 1, pp. 158-173, 2002.

[44] C. Soares and J. C. Brito, "Environmental correlates for species richness among amphibians and reptiles in a climate transition area," Biodiversity and Conservation, vol. 16, no. 4, pp. 1087-1102, 2007.

[45] N. Sauberer, K. P. Zulka, M. Abensperg-Traun et al., "Surrogate taxa for biodiversity in agricultural landscapes of eastern Austria," Biological Conservation, vol. 117, no. 2, pp. 181-190, 2004.

[46] A. Bitz, K. Fischer, L. Simon et al., Die Amphibien und Reptilien in Rheinland-Pfalz, GNOR-Eigenverlag, Landau, Germany, 1996.
[47] R. Günther, Die Amphibien und Reptilien Deutschlands, Gustav Fischer, Jena, Germany, 1996.

[48] N. Balagurova, S. Drozdov, and S. Grabovik, "Cold and heat resistance of five species of Sphagnum," Annales Botanici Fennici, vol. 33, no. 1, pp. 33-37, 1996.

[49] C. Hassall and D. J. Thompson, "Accounting for recorder effort in the detection of range shifts from historical data," Methods in Ecology and Evolution, vol. 1, pp. 343-350, 2010.

[50] C. E. Steck and M. Pautasso, "Human population, grasshopper and plant species richness in European countries," Acta Oecologica, vol. 34, no. 3, pp. 303-310, 2008.

[51] T. Wohlgemuth, "Modelling floristic species richness on a regional scale: a case study in Switzerland," Biodiversity and Conservation, vol. 7, no. 2, pp. 159-177, 1998.

[52] M. Bakkenes, J. R. M. Alkemade, F. Ihle, R. Leemans, and J. B. Latour, "Assessing effects of forecasted climate change on the diversity and distribution of European higher plants for 2050," Global Change Biology, vol. 8, no. 4, pp. 390-407, 2002.

[53] T. M. Caro and G. O’Doherty, "On the use of surrogate species in conservation biology," Conservation Biology, vol. 13, no. 4, pp. 805-814, 1999.

[54] E. Fleishman, J. R. Thomson, R. Mac Nally, D. D. Murphy, and J. P. Fay, "Using indicator species to predict species richness of multiple taxonomic groups," Conservation Biology, vol. 19, no. 4, pp. 1125-1137, 2005.

[55] S. Lovell, M. Hamer, R. Slotow, and D. Herbert, "Assessment of congruency across invertebrate taxa and taxonomic levels to identify potential surrogates," Biological Conservation, vol. 139, no. 1-2, pp. 113-125, 2007.

[56] A. Schuldt, Z. Wang, H. Zhou, and T. Assmann, "Integrating highly diverse invertebrates into broad-scale analyses of crosstaxon congruence across the Palaearctic," Ecography, vol. 32, no. 6, pp. 1019-1030, 2009.

[57] P. Duelli and M. K. Obrist, "In search of the best correlates for local organismal biodiversity in cultivated areas," Biodiversity and Conservation, vol. 7, no. 3, pp. 297-309, 1998.

[58] D. L. Pearson and S. S. Carroll, "The influence of spatial scale on cross-taxon congruence patterns and prediction accuracy of species richness," Journal of Biogeography, vol. 26, no. 5, pp. 1079-1090, 1999.

[59] C. Moritz, K. S. Richardson, S. Ferrier et al., "Biogeographical concordance and efficiency of taxon indicators for establishing conservation priority in a tropical rainforest biota," Proceedings of the Royal Society B, vol. 268, no. 1479, pp. 1875-1881, 2001.

[60] Fauna Europaea, "Fauna Europaea version 2.4," 2009, http:// www.faunaeur.org/.

[61] J. R. Prendergast, R. M. Quinn, J. H. Lawton, B. C. Eversham, and D. W. Gibbons, "Rare species, the coincidence of diversity hotspots and conservation strategies," Nature, vol. 365, no. 6444, pp. 335-337, 1993. 

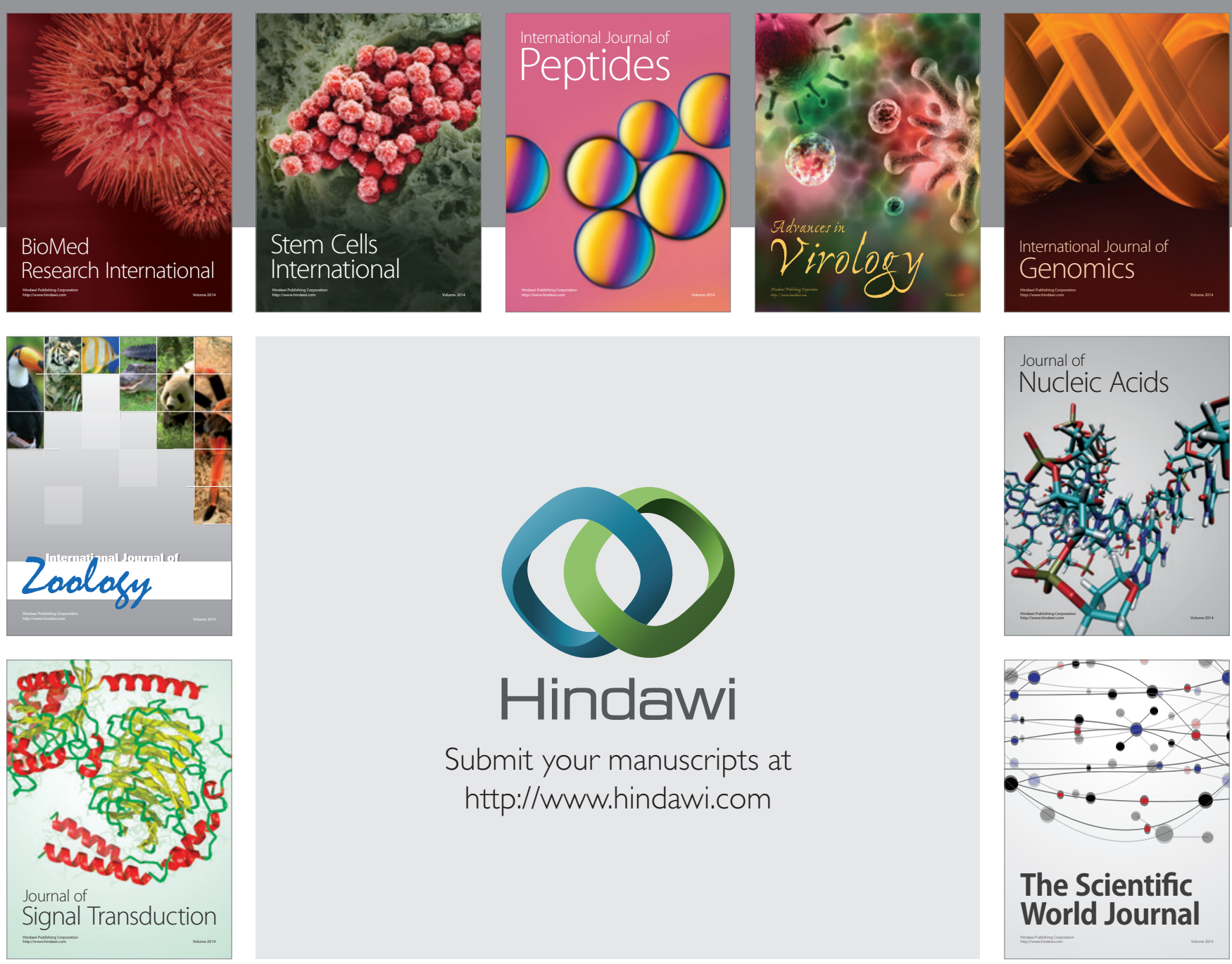

Submit your manuscripts at

http://www.hindawi.com
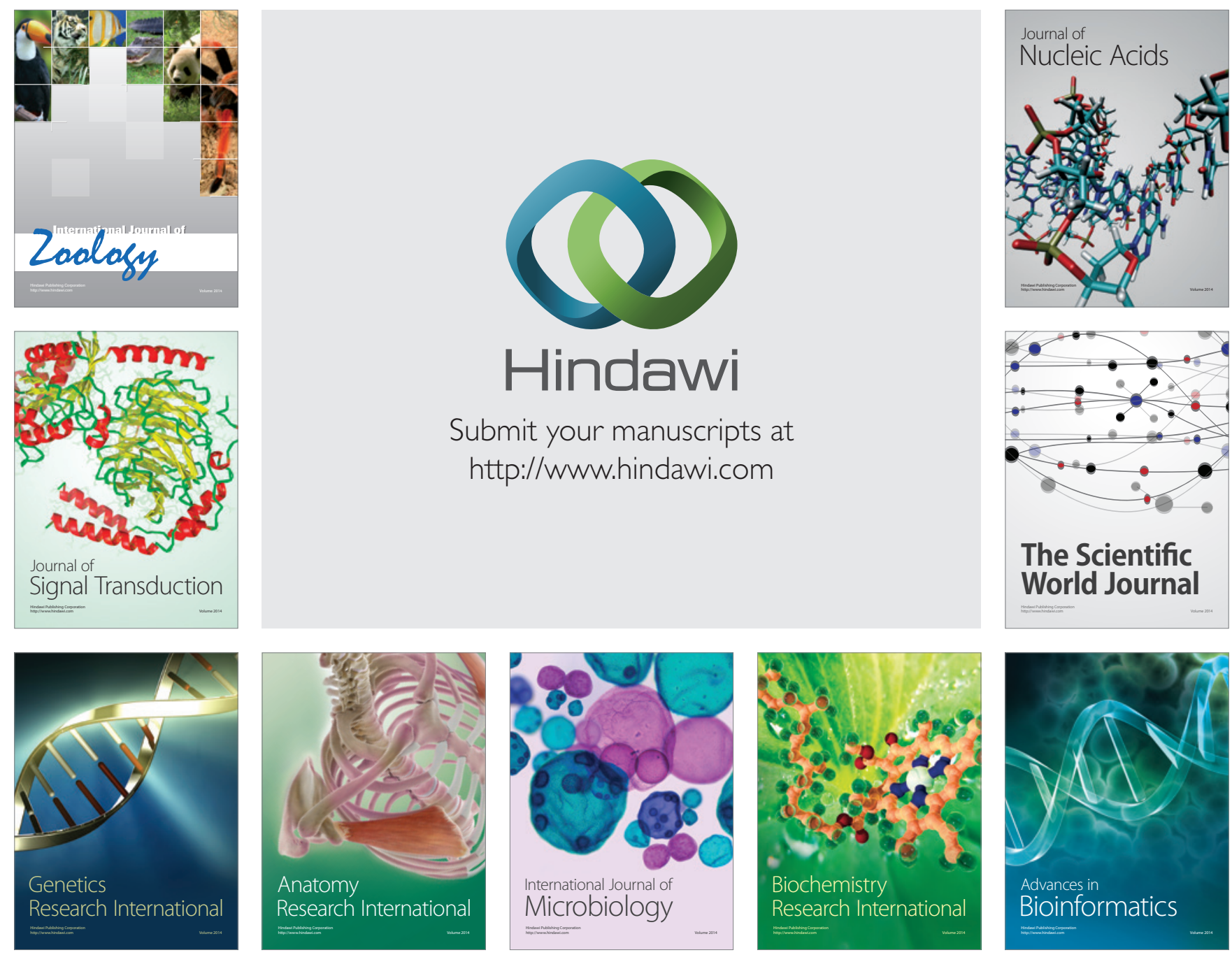

The Scientific World Journal
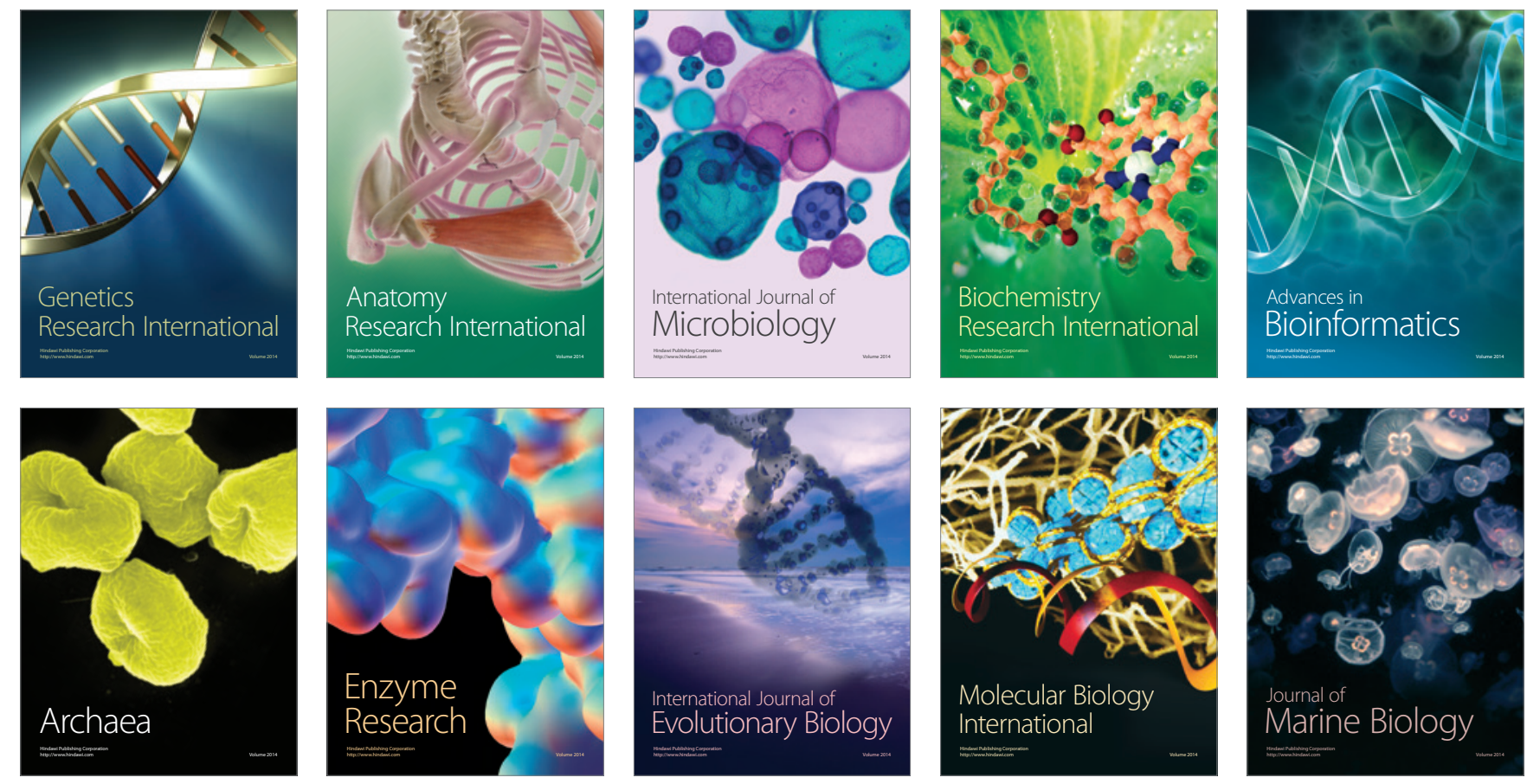